Doi: 10.35414/akufemubid.503565

Araştırma Makalesi / Research Article

\title{
\%20 Pyridaben İçeren Primite 20 WP'nin Allium cepa Kök Meristematik Hücrelerine Üzerine Sitotoksik ve Genotoksik Etkileri
}

\author{
Recep Liman ${ }^{1}$ \\ ${ }^{1}$ Uşak Üniversitesi, Fen Edebiyat Fakültesi, Moleküler Biyoloji ve Genetik Bölümü, Uşak \\ ID: https://orcid.org/0000-0002-7944-4952 \\ e-posta: recep.liman@usak.edu.tr.
}

Anahtar kelimeler Allium; Komet;

Akarasit; İnsektisit; DNA hasarı

\section{Öz}

\%20 Pyridaben içeren Primite 20 WP (PIP) akarisit ve insektisit olarak kullanılmaktadır. Bu çalışmada PiP'in sitotoksik ve genotoksik etkileri Allium cepa kök meristematik hücrelerinde kök büyümesi, mitotik indeks (Mi), kromozomal anormallik (KA)'ler ve DNA hasarı üzerindeki etkileri Allium ana-telofaz ve Komet testleri kullanılarak araştırımıştır. Allium kök büyüme engelleme testi ile PiP'in kök uçlarının büyümesini negatif kontrol grubuna göre \%50 oranında düşüren konsantrasyon $\left(E_{50}\right)$ değeri, 50 ppm olarak bulunmuştur. A. cepa kökleri PiP'in üç farklı konsantrasyonu (25, 50 ve 100 ppm), distile su (negatif kontrol) ve metil metan sülfonata (MMS, 10 ppm, pozitif kontrol) 24, 48, 72 ve 96 saat maruz bırakılmıştır. PiP; kök büyümesini ve Mi'yi istatistiksel olarak azaltarak sitotoksik etki, KA'ları (bozulmuş ana-telofaz, kalgın kromozom, yapışıkık, köprü ve poliploidi) ve DNA hasarını istatistitiksel olarak artırarak genotoksik etki göstermiştir. PiP kullanımına dikkat edilmeli ve sito-genotoksik etkileri diğer toksisite test sistemleri ile araştırılmalıdır.

\section{Cytotoxic and Genotoxic Effects of Primite 20 WP Containing 20\% Pyridaben on Allium cepa Root Meristematic Cells}

\begin{abstract}
Primite 20 WP containing $20 \%$ pyridaben (PCP) is used as an acaricide and insecticide. In this study, cytotoxic and genotoxic effects of PCP were investigated on the root meristem cells of Allium cepa for its effects on root growth, mitotic index (MI), mitotic phases, chromosomal abnormalities (CAs) and DNA damage by using Allium ana-telophase and Comet assays. The amount of PCP concentration that reduces the growth of root tips by $50 \%$ compared to the negative control group $\left(\mathrm{EC}_{50}\right)$ value was determined as $50 \mathrm{ppm}$ by Allium root growth inhibition test. A. cepa roots were treated with three concentrations of $\operatorname{PCP}(25,50$ and $100 \mathrm{ppm})$, distilled water (negative control) and methyl methane sulphonate (MMS, 10 ppm, positive control) for 24, 48, 72 and $96 \mathrm{~h}$. PCPshowed a cytotoxic effect by reducing root growth and $\mathrm{Ml}$, but also showed genotoxic effect by increasing CAs (disturbed anatelophase, chromosome laggards, stickiness, bridges and polyploidy) and DNA damage at significant levels. PCPshould be used carefully and investigated its cyto-genotoxic effects with other toxicology test systems.
\end{abstract}

(c) Afyon Kocatepe Üniversitesi

\section{Giriş}

\%20 Pyridaben içeren Primite 20 WP (PIP), narenenciyede Pas Böcüsü (Phyllocoptrata oleviora) ve Turunçgil Kırmızı Örümceğine (Panonychus citru) karşı, elmada Avrupa Kırmızı Örümceği ( $P$. ulmi) ve İki Noktalı Kırmızı Örümceğine (Tetranychus urticae) karşı, domateste ise Beyaz Sinek (Bemisia tabaci) ve Pas akarına (Aculops lycopersici) karşı akarisit ve 
insektisit olarak yaygın bir biçimde kullanılmaktadır (Int Kyn. 1, Igarashi and Sakamota 1994, Rand and Clark 2000). Pyridaben kimyasal olarak pyridazinone grubu pestisitlerin tek üyesini oluşturmaktadır (Yu 2008). Böcek ve akarlarda mitokondriyel elektron taşıma sistemindeki Kompleks I'i inhibe ederek iş görmektedirler (Gomez et al. 2007, Bose and Beal 2016). Pyridabenin kimyasal yapısı Şekil 1'de verilmiştir.

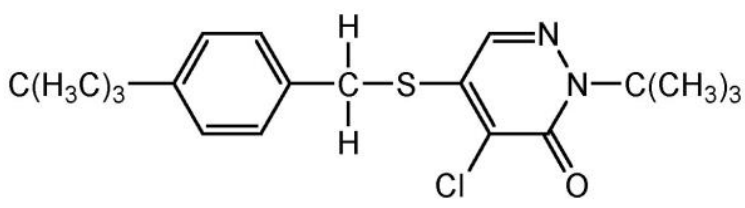

Şekil 1. Pyridabenin kimyasal yapısı

Birleşmiş Milletler Çevre Programı, Dünya Sağlık Örgütü ve Amerika Birleşik Devletleri Çevre Koruma Ajansı tarafından onaylanmış olan Allium testi, kimyasalların toksisite ve genotoksisitesini belirlenmek için kullanılan hassas, basit, tekrarlanabilirliği yüksek ve ucuz olan sitogenetik bitki sistemlerinden birisidir. Ayrıca testin sonuçları diğer biyolojik test sistemleri ile de iyi korelasyon göstermektedir. Bu test sisteminde büyüme ve $\mathrm{EC}_{50}$ gibi makroskobik, Mi ve KA'lar (c-mitoz, kalgın kromozom, yapışıklık v.s) gibi mikroskobik parametreler kolaylıkla değerlendirilebilmektedir (Fiskesjö 1985, Caritá and Marin-Morales 2008, Chaparro et al. 2010, Mauro et al. 2014, Liman et al. 2015, 2019, Palmieri et al. 2016, Rahman et al. 2017).

Komet testi ya da tek hücre jel elektroforezi; basit, hızlı, duyarlı, nispeten düşük maliyetli olması ve az sayıda hücreden güçlü sonuçlar elde edilebilmesinden dolayı kimyasalların genotoksisitelerinin belirlenmesi için geliştirilmiş iyi bir tekniktir. A. cepa kök meristem hücreleri Allium testindeki mitozdan bağımsız olarak Komet testi ile DNA hasarını tespit etmek için de kullanılmaktadır (Gichner et al. 2009, Liman 2013, Kaya et al. 2015, Santos et al. 2015, Dhawan and Anderson 2016, Jana et al. 2017, Kaygisiz and Ciğerci 2017, Küçük and Liman 2018).

Bu çalışmada pyridabenin ticari formu olan PiP'in $A$. cepa kök ucu meristem hücrelerinde sitogenetik ve genotoksik etkileri Allium ana-telofaz ve Komet testi ile araştırılmıştır.

\section{Materyal ve Metot}

A. cepa $(2 \mathrm{n}=16)$ ticari olarak süpermarketten, PiP ise Safa Tarım Konya'dan temin edilmiştir. Bazik Fuksin (CAS No 569-61-9), MMS (CAS No 66-27-3), Düşük Erime Noktalı Agaroz (LMPA, CAS No 39346-81-1), Normal Erime Noktalı Agaroz (NMPA, CAS No 9012 36-6), Trizma Baz (CAS No 77-86-1), Etilendiamintetraasetik asit (CAS No 6381-92-6), Sodyum Hidroksit (CAS No 1310-73-2), Trizma Hidroklorik Asit (CAS No 1185-53-1), Sodyum Klorür (CAS No 7647-14-5), Potasyum Klorür (CAS No 744740-7), Sodyum Fosfat Dibazik-Heptahidrat (CAS No 7782-85-6), Potasyum Fosfat Monobazik (CAS No 7778-77-0), Triton-X100 (CAS No 9002-93-1), Magnezyum Klorür Hekzahidrat (CAS No 7791-18-6), Etidyum Bromür (CAS No 1239-45-8), Hidroklorik Asit (CAS No 7647-01-0), Asetik Asit (CAS No 64-197), Etanol (CAS No 64-17-5) ve Potasyum Disülfit (CAS No 16731-55-8) Sigma Aldrich'ten (Almanya) satın alınmıştır.

\subsection{Allium ana-telofaz testi}

\subsubsection{Büyümeyi Engelleme Testi}

Büyümeyi engelleme testi Fiskesjö (1985) metodunda bazı değişiklikler yapılarak PiP'in A. cepa kök meristem hücrelerinde $\mathrm{EC}_{50}$ değeri belirlenmiştir. Yaklaşık aynı büyüklükteki soğanların (1-2 cm çapında) kahverengi kabukları soyulmuş ve çimlenmiş olan kökleri, kök primordiyalarına zarar vermeyecek şekilde temizlenmiştir. PiP'in çeşitli konsantrasyonları $(25,50,75,100,125,150$ ve 200 ppm) ve distile su (negatif kontrol grubu) karanlık ortamda oda sıcaklığında $\left(\sim 21^{\circ} \mathrm{C} \pm 4{ }^{\circ} \mathrm{C}\right) 96$ saat boyunca çimlenmeye bırakılmıştır. Çözeltiler her gün yenilenmiştir. Uygulama grupları için beşer tane soğan kullanılmıştır. Süre sonunda her bir soğandan onar adet olmak üzere toplamda ellişer kök alınarak ortalama kök uzunlukları belirlenmiştir.

\subsubsection{Mitotik Aktivite ve Kromozom Anormalliklerin Belirlenmesi}

Soğanların köklerini 2-3 cm uzunluğuna ulaşmasını sağlamak için 2 gün boyunca distile suda köklendirildikten sonra; PiP'in $2 \times \mathrm{EC}_{50}, \quad \mathrm{EC}_{50}$ ve 
1/2xEC $\mathrm{C}_{50}$ konsantrasyonları, distile su (negatif kontrol) ve MMS (10 ppm, pozitif kontrol) 24,48,72 ve 96 saat boyunca karanlık ortamda oda sıcaklığında çimlendirilmeye bırakılmıştır. Uygulama grupları için üçer adet soğan kullanılmıştır. Tespit işlemi için her bir uygulama için 15-20 kök yaklaşık 1 $\mathrm{cm}$ uzunluğunda kesilerek $4{ }^{\circ} \mathrm{C}^{\prime}$ de Carnoy fiksatifi içerisinde 24 saat bekletilmiştir. Süre sonunda kökler \% $70^{\prime}$ lik alkol içerisine alınarak $4{ }^{\circ} \mathrm{C}^{\prime}$ de deney yapılıncaya kadar bekletilmiştir. Mi ve KA'ların belirlenmesinde bu kök uçları kullanılmıştır. Kök uçları distile su ile yıkandıktan sonra $1 \mathrm{~N} \mathrm{HCl}$ ile 60 ${ }^{\circ} \mathrm{C}$ 'de 8-10 dakika bekletilerek hidrolize edilmiştir. Kökler distile su ile tekrar yıkanarak oda sıcaklığında Feulgen tekniği ile 25-30 dakika boyanmıştır. Koyu boyanan kök uçları kesilerek \%45'lik asetik asit ile ezme preparatları yapılmış ve tırnak cilası ile yarı daimi hale getirilmiştir. Mi ve KA'ların tespiti Saxena et al. (2005)'a göre CMOS kamera (Argenit, Kameram5, Türkiye) ataçmanlı Nikon Eclipse Ci-L ışık mikroskobu (Japonya) ile yapılmıştır. Her bir uygulama için 5000-6000 (preparat başına 10001200) hücre sayılarak, sayılan hücreler arasında mitoza girenlerin yüzdesi hesaplanarak Mi değeri hesaplanmıştır. Her bir uygulama için 500 anatelofaz hücresi (Slayt başına 100 hücre) sayılarak KA'lar (bozulmuş ana-telofaz, kalgın kromozom, yapışkanlık, anafaz köprüsü ve poliploidi) belirlenerek fotoğrafları $x 40$ objektifte çekilmiştir. Mi ve KA aşağıdaki formüllere göre hesaplanmıştır.

$\mathrm{Mi}=$ (Mitoza girmiş hücre sayısı/Toplam hücre sayısı) x 100

$\mathrm{KA}=$ (Toplam anormal Hücre/Toplam sayılan anatelofaz hücre sayısı) x 100

\subsection{Komet testi}

Komet testi Tice et al. (2000) metodunda bazı değişiklikler yapılarak DNA hasarını belirlemek için yapılmıştır. 2.1.2' de belirtildiği gibi $A$. cepa kökleri, hazırlanan uygulama gruplarına belirtilen sürelerde maruz bırakılmışlardır. Süreler sonunda soğanlardan her konsantrasyon için her soğandan yedişer kök kesilmiştir. Her bir uygulama için üç tekrar yapılmıştır. Nukleus izolasyonu Liman et al. (2015)'a göre yapılmıştır. $50 \mu \mathrm{L}$ örnek, $50 \mu \mathrm{L} \% 1.5^{\prime}$ lik LMPA ile $37^{\circ} \mathrm{C}^{\prime}$ de karıştırıldıktan sonra daha önceden $\% 1^{\prime}$ lik
NMPA ile kaplanmış lamlara yayılarak üzeri lamelle kapatılmıştır. İşlem sonunda buz kasetleri üzerinde 5 dakika bekletilmiştir. Örnekler elektroforez tankına alınarak elektroforez tampon çözeltisi (300 mM NaOH ve 1 mM EDTA, $p H>13$ ) içinde cihaz çalıştırılmadan $4{ }^{\circ} \mathrm{C}^{\prime}$ de 25 dakika bekletilmiştir. Ardından 25V, 300 mA'da 20 dakika $4{ }^{\circ} \mathrm{C}^{\prime}$ de elektroforez edilmiştir. Preparatlar 5 dakika distile suda bekletildikten sonra 0.4 M Tris ( $\mathrm{pH} 7.5$ ) çözeltisi ile üç kez beşer dakika aralıklarla nötralize edilmiştir. Her bir preparat $70 \mu \mathrm{L}$ Etidyum Bromür $(20 \mu \mathrm{g} / \mathrm{mL})$ ile 5 dakika boyanmıştır. CCD kamera (BAB, TC-5, Türkiye) ataçmanlı Floresan mikroskobu (BAB, TAM$F$, Türkiye) kullanılarak her bir slaytta 50 komet görsel olarak Koçyigit et al. (2005)'a göre değerlendirilmiştir (0-hasarsız, 1-hafif hasar, 2-orta hasar, 3-ciddi hasar, 4- tam hasar). DNA hasarının derecesi ifade etmek için aşağıdaki denklem kullanılmıştır:

Arbitrary unit $=\sum_{i=0}^{4} N i * i$

$\mathrm{Ni}=\mathrm{I}$ derecesindeki hücrelerin sayısı; $\mathrm{i}$ = hasar derecesi $(0,1,2,3,4)$

\section{3 istatistiksel değerlendirme}

Sonuçların (ortalama \pm standart sapma) karşılaştırılması SPSS 23.0 for Windows paket programında Duncan çoklu dağılım testi ile yapılmıştır $(P<0.05)$. Doz-cevap ve süre-cevap ilişkisi ise Pearson korelasyon testi ile belirlenmiştir.

\section{Bulgular}

\subsection{Büyümeyi Engelleme Testi}

$\mathrm{Bu}$ testte PiP'in çeşitli konsantrasyonları ve saf su (negatif kontrol) 96 saat boyunca çimlenmeye bırakılarak ortalama kök uzunlukları belirlenmiştir. Kontrol grubundan ortalama kök uzunluğu $3.5 \pm 0.11$ $\mathrm{cm}$ iken PiP'in uygulanan konsantrasyonlarında bu değer $2.93 \pm 0.12$ ile $0.94 \pm 0.07 \mathrm{~cm}$ arasında değişmektedir. Azalan bu değerler kontrol grubuna göre istatistiksel olarak anlamlı bulunmuştur (Çizelge 1). PiP'in $E C_{50}$ değeri 100 ppm olarak bulunmuştur. PiP'in uygulanan bütün dozları ortalama kök uzunluğunu doza bağımlı bir şekilde istatistiksel olarak azaltmıştır ( $r=-0,977 p=0,01) .200$ ppm'lik uygulamada kontrol grubuna göre $\% 67,92$ oranında azalma tespit edilmiştir. 


\subsection{PiP'in Mitotik indeks ve Kromozom Anormallikleri Üzerine Etkisi}

PiP'in A. cepa kök hücrelerindeki Mi ve mitotik fazlara olan etkisi Çizelge 2'de gösterilmiştir. PiP'in uygulanan tüm dozları, Mi değerini, kontrol grubuna göre istatistiksel olarak anlamlı derecede azaltmıştır. Bu azalışlar hem doza bağlı (24 saat için $r=-0.98 p=0.01,48$ saat için $r=-0.95 p=0.01,72$ saat için $r=-0.877 p=0.01$ ve 96 saat için $r=-0.953 p=0.01$ ) hem de zamana bağlı olarak (50 ppm için $r=-0.981$ $\mathrm{p}=0.01,100 \mathrm{ppm}$ için $\mathrm{r}=-0.981 \mathrm{p}=0.01$ ve $200 \mathrm{ppm}$ için $r=-0.964 \mathrm{p}=0.01$ ) istatistiksel açıdan anlamlı bulunmuştur. PiP'in en yüksek Mi değerine 24 saatlik uygulamadaki 50 ppm'lik konsantrasyonunda (69.23 \pm 0.32 ), en düşük $\mathrm{Mi}$ değerine ise 96 saatlik uygulamadaki 200 ppm'lik konsantrasyonunda (55.38 \pm 0.31$)$ görülmüştür. PiP'in uygulanan tüm dozları profaz indeksini kontrol grubuna göre istatistiksel olarak azaltmışken telofaz indeksini arttırmıştır.

Çizelge 1. PIP'in A. cepa köklerinde büyümeyi engelleme testi sonuçları

\begin{tabular}{cccc}
\hline & $\begin{array}{c}\text { Ortalama } \\
\text { uzunluk } \\
\text { cm } \pm \text { SS* }\end{array}$ & $\begin{array}{c}\% \\
\text { Büyüme }\end{array}$ & $\begin{array}{c}\% \\
\text { Büyümede } \\
\text { azalma }\end{array}$ \\
\hline $\begin{array}{c}\text { Kontrol } \\
\mathbf{2 5}\end{array}$ & $\begin{array}{c}2.5 \pm 0.11 \mathrm{a} \\
\mathbf{5 0}\end{array}$ & 100 & 0 \\
$\mathbf{7 5}$ & $2.43 \pm 0.12 \mathrm{~b}$ & 83,71 & 16,29 \\
$\mathbf{1 0 0}$ & $\mathbf{1 . 7 6} \pm 0.13 \mathrm{c}$ & 69,43 & 30,57 \\
$\mathbf{1 2 5}$ & $1.58 \pm 0.12 \mathrm{f}$ & 58,86 & 41,14 \\
$\mathbf{1 5 0}$ & $1.28 \pm 0.11 \mathrm{~g}$ & $\mathbf{5 0 , 2 9}$ & $\mathbf{4 9 , 7 1}$ \\
$\mathbf{2 0 0}$ & $0.94 \pm 0.07 \mathrm{~h}$ & 32,08 & 54,86 \\
\hline
\end{tabular}

*Sütunlardaki farklı harfler $\mathrm{p}<0.05$ düzeyinde anlamlı (Duncan çoklu dağılım testi) SS: Standart sapma

Çizelge 2. PiP'in A. cepa kök hücrelerindeki Mi ve mitotik fazlara olan etkisi

\begin{tabular}{|c|c|c|c|c|c|c|}
\hline \multirow{2}{*}{$\begin{array}{l}\text { Konsantrasyon } \\
\text { (ppm) }\end{array}$} & \multirow{2}{*}{$\begin{array}{l}\text { Sayılan } \\
\text { Hücre }\end{array}$} & \multirow{2}{*}{$\begin{array}{l}\text { Mitotik } \\
\text { Indeks } \\
\pm \text { SS }\end{array}$} & \multicolumn{4}{|c|}{ Mitotik Faz Safhaları (\%) \pm SS* } \\
\hline & & & Profaz & Metafaz & Anafaz & Telofaz \\
\hline Kontrol- 24 saat & 5080 & $71.69 \pm 0.61 a$ & $89.35 \pm 0.79 a$ & $1.81 \pm 0.19 a$ & $2.45 \pm 0.28 a$ & $6.39 \pm 0.6 a$ \\
\hline MMS-10 & 5152 & $58.92 \pm 0.44 b$ & $85.01 \pm 0.18 b$ & $2.68 \pm 0.18 b$ & $2.81 \pm 0.15 b$ & $9.49 \pm 0.28 b$ \\
\hline 50 & 5116 & $69.23 \pm 0.32 c$ & $86.51 \pm 0.28 c$ & $1.92 \pm 0.07 a$ & $2.26 \pm 0.16 a$ & $9.32 \pm 0.15 b$ \\
\hline 100 & 5085 & $66.45 \pm 0.12 d$ & $87.51 \pm 0.38 d$ & $1.57 \pm 0.17 \mathrm{c}$ & $1.36 \pm 0.12 c$ & $9.56 \pm 0.26 b$ \\
\hline 200 & 5121 & $62.26 \pm 0.84 \mathrm{e}$ & $87.20 \pm 0.16 \mathrm{~d}$ & $1.54 \pm 0.15 c$ & $1.63 \pm 0.1 d$ & $9.63 \pm 0.19 b$ \\
\hline Kontrol- 48 saat & 5132 & $70.46 \pm 0.87 a$ & $89.37 \pm 0.66 a$ & $1.83 \pm 0.14 a$ & $2.36 \pm 0.25 a$ & $6.44 \pm 0.31 a$ \\
\hline MMS-10 & 5137 & $56.92 \pm 0.68 b$ & $85.43 \pm 0.29 b$ & $2.39 \pm 0.17 b$ & $2.6 \pm 0.13 b$ & $9.57 \pm 0.21 b$ \\
\hline 50 & 5101 & $65.18 \pm 0.64 c$ & $86.6 \pm 0.33 c$ & $1.86 \pm 0.13 a$ & $2.22 \pm 0.12 a$ & $9.32 \pm 0.26 b$ \\
\hline 100 & 5074 & $63.52 \pm 0.39 d$ & $87.71 \pm 0.07 d$ & $1.46 \pm 0.21 \mathrm{c}$ & $1.24 \pm 0.16 c$ & $9.59 \pm 0.2 b$ \\
\hline 200 & 5120 & $60.45 \pm 0.73 e$ & $87.98 \pm 0.41 d$ & $1.2 \pm 0.18 \mathrm{~d}$ & $1.16 \pm 0.15 c$ & $9.66 \pm 0.33 b$ \\
\hline Kontrol-72 saat & 5167 & $70.66 \pm 0.88 a$ & $89.23 \pm 0.31 a$ & $1.85 \pm 0.12 \mathrm{ab}$ & $2.4 \pm 0.16 a$ & $6.52 \pm 0.33 a$ \\
\hline MMS-10 & 5183 & $53.69 \pm 0.62 b$ & $85.53 \pm 0.39 b$ & $2.07 \pm 0.28 a$ & $2.32 \pm 0.2 a$ & $10.07 \pm 0.42 b$ \\
\hline 50 & 5094 & $62.34 \pm 0.84 c$ & $86.51 \pm 0.45 c$ & $1.71 \pm 0.21 b$ & $1.93 \pm 0.19 b$ & $9.86 \pm 0.42 b$ \\
\hline 100 & 5081 & $61.45 \pm 0.55 c$ & $87.76 \pm 0.52 d$ & $1.41 \pm 0.12 c$ & $1.19 \pm 0.21 c$ & $9.64 \pm 0.59 b$ \\
\hline 200 & 5098 & $58.36 \pm 0.81 d$ & $88.33 \pm 0.33 e$ & $0.98 \pm 0.14 d$ & $0.81 \pm 0.13 d$ & $9.88 \pm 0.19 \mathrm{~b}$ \\
\hline Kontrol- 96 saat & 5170 & $71.6 \pm 0.85 a$ & $89.21 \pm 0.31 a$ & $1.85 \pm 0.18 a$ & $2.43 \pm 0.22 a$ & $6.51 \pm 0.28 a$ \\
\hline MMS-10 & 5212 & $50.42 \pm 0.92 b$ & $85.52 \pm 0.37 b$ & $1.80 \pm 0.25 a$ & $2.23 \pm 0.27 a$ & $10.45 \pm 0.43 b$ \\
\hline 50 & 5148 & $59.79 \pm 0.64 c$ & $86.45 \pm 0.55 c$ & $1.59 \pm 0.24 a$ & $1.78 \pm 0.12 b$ & $10.18 \pm 0.59 b$ \\
\hline 100 & 5128 & $57.16 \pm 0.75 d$ & $88.33 \pm 0.66 d$ & $0.85 \pm 0.24 b$ & $0.89 \pm 0.15 c$ & $9.93 \pm 0.65 b$ \\
\hline 200 & 5204 & $55.38 \pm 0.31 \mathrm{e}$ & $88.03 \pm 0.45 d$ & $0.83 \pm 0.14 b$ & $0.76 \pm 0.2 c$ & $10.38 \pm 0.24 b$ \\
\hline
\end{tabular}

*Sütunlardaki farklı küçük harfler $p<0.05$ düzeyinde önemli (Duncan çoklu dağılım testi) SS: Standart Sapma Pip'in A. cepa kök meristematik hücrelerinde anormallik 96 saatlik uygulamanın 200 ppm'lik indüklediği toplam KA'lara bakıldığında en fazla dozunda $(\% 14.8 \pm 0,54)$, en az anormallik olayına ise 
24 saatlik uygulamanın 50 ppm'lik dozunda (\%7.8 \pm 0.45 ) rastlanılmıştır (Çizelge 3 ). Uygulanan süre ve artan dozlara göre toplam anormalliklerdeki yüzde değişimler, kontrole göre istatistiksel olarak anlamlı bulunmuştur. Toplam KA'larda doza (24 saat için $r=0.9=0.01$; 48 saat için $r=0.833 p=0.01 ; 72$ saat için $r=0.529 p=0.05$ ve 96 saat için $r=0.8 p=0,01$ ) ve zamana bağlı bir artış gözlemlenmiştir (50 ppm için $r=0.94 p=0.01,100 \mathrm{ppm}$ için $r=0.915 p=0.01$ ve 200 ppm için $r=0.954 p=0.01$ ). PiP'in 200 ppm'lik dozundaki toplam anormallikler 24 saatlik uygulama hariç pozitif kontrol grubu olan MMS'den yüksek bulunmuştur ancak bu artışlar istatistiksel olarak anlamlı bulunmamıştır. PiP'in ana-telofaz safhasında neden olduğu anormallikler; bozulmuş ana-telofaz, kalgın kromozom, yapışkanlık, anafaz köprüsü ve poliploidir (Şekil 2). PiP'in indüklediği bozulmuş ana-telofaz (\%3.6, 200 ppm 96 saat) en fazla gözüken anormallik iken anafaz köprüsü (\%0.8,
100 ppm 24 saat) en az gözüken anormallik ise anafaz köprüsüdür (\%0.8, 100 ppm 24 saat).

\subsection{Komet Testi Sonuçları}

Komet testi PiP'in $A$. cepa kök meristematik hücreleri üzerinde oluşturduğu DNA hasarını belirlemek için yapılmıştır (Çizelge 4). PiP'in bütün dozları DNA hasarını kontrol grubuna göre istatistiksel olarak arttırmış olup bu artışlar hem doza (24 saat için $r=0.989=0.01$; 48 saat için $r=0.98$ $p=0.01 ; 72$ ve 96 saat için $r=0.956 p=0.01$ hem de zamana (50 ppm için $r=0.983 p=0.01,100$ ppm için $r=0.947 p=0.01$ ve 200 ppm için $r=0.93 p=0.01$ ) bağımlı bulunmuştur. Ancak bu artışlar pozitif kontrol grubu olan MMS'den düşük bulunmuştur. PiP'in oluşturduğu en yüksek DNA hasarına 200

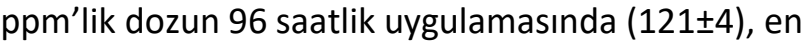
düşük DNA hasarına ise 50 ppm'lik dozun 24 saatlik uygulamasında (43 \pm 2 ) rastlanılmıştır.

Çizelge 3. PiP'in A. cepa kök meristematik hücrelerinde indüklediği KA'lar

\begin{tabular}{|c|c|c|c|c|c|c|c|}
\hline \multirow[b]{2}{*}{$\begin{array}{c}\text { Konsantrasyon } \\
\text { (ppm) }\end{array}$} & \multirow[b]{2}{*}{$\begin{array}{l}\text { İncelenen } \\
\text { Hücre } \\
\text { Sayısı }\end{array}$} & \multirow[b]{2}{*}{$\begin{array}{l}\text { Bozulmuş } \\
\text { anafaz- } \\
\text { telofaz }\end{array}$} & \multicolumn{5}{|c|}{ Ana-telofazdaki Anormallikler ( \% ) } \\
\hline & & & $\begin{array}{c}\text { Kalgın } \\
\text { kromozom }\end{array}$ & Yapışkanlık & $\begin{array}{l}\text { Anafaz } \\
\text { köprüsü }\end{array}$ & Poliploidi & $\begin{array}{c}\text { Toplam } \\
\text { Anormallikler } \\
\text { ( \%₫ SS ) }\end{array}$ \\
\hline Kontrol- 24 saat & 500 & 0,8 & 0,6 & 0,8 & 0,4 & 0,6 & $3,2 \pm 0,45 a$ \\
\hline MMS-10 & 500 & 2,4 & 2,4 & 3 & 1,4 & 1,4 & $10,6 \pm 0,89 b$ \\
\hline 50 & 500 & 2 & 1,4 & 2 & 1,4 & 1 & $7,8 \pm 0,45 c$ \\
\hline 100 & 500 & 2,4 & 1,8 & 3 & 0,8 & 1 & $9 \pm 0,71 d$ \\
\hline 200 & 500 & 2,6 & 1,8 & 3 & 1,4 & 1,2 & $10 \pm 0 b$ \\
\hline Kontrol- 48 saat & 500 & 1 & 0,8 & 1 & 0,4 & 0,6 & $3,8 \pm 0,45 a$ \\
\hline MMS-10 & 500 & 3,6 & 2,4 & 2,2 & 2,2 & 1,2 & $11,6 \pm 0,55 b$ \\
\hline 50 & 500 & 2,2 & 1,8 & 2,2 & 1,4 & 1,4 & $9 \pm 1 c$ \\
\hline 100 & 500 & 2,8 & 2,6 & 2,4 & 1,8 & 1,6 & $11,2 \pm 0,84 b$ \\
\hline 200 & 500 & 3,2 & 2,4 & 3,2 & 2 & 1,4 & $12,2 \pm 0,84 b$ \\
\hline Kontrol-72 saat & 500 & 0,8 & 0,6 & 0,6 & 0,6 & 0,8 & $3,4 \pm 0,55 a$ \\
\hline MMS-10 & 500 & 3 & 2,6 & 2,8 & 3,2 & 1,6 & $13,2 \pm 0,84 b$ \\
\hline 50 & 500 & 2,6 & 2,6 & 3,4 & 2 & 1,8 & $12,4 \pm 0,55 b$ \\
\hline 100 & 500 & 2,8 & 2,8 & 3 & 2,8 & 1,6 & $13 \pm 1 b$ \\
\hline 200 & 500 & 2,2 & 3,4 & 3,2 & 2,4 & 2,2 & $13,4 \pm 0,55 b$ \\
\hline Kontrol- 96 saat & 500 & 0,6 & 1 & 0,4 & 0,6 & 0,6 & $3,2 \pm 0,84 a$ \\
\hline MMS-10 & 500 & 2,8 & 3,2 & 2,6 & 3 & 2,8 & $14,4 \pm 0,55 b c$ \\
\hline 50 & 500 & 2,4 & 2,2 & 3 & 3 & 2,6 & $13,2 \pm 0,45 b$ \\
\hline 100 & 500 & 3 & 3 & 2,8 & 2,6 & 2,6 & $14 \pm 0,71 c$ \\
\hline 200 & 500 & 2 & 3,6 & 3,4 & 2,4 & 3,4 & $14,8 \pm 0,45 c$ \\
\hline
\end{tabular}

* Sütunlardaki farklı harfler $p<0.05$ düzeyinde önemli (Duncan çoklu dağılım testi) SS: Standart Sapma 


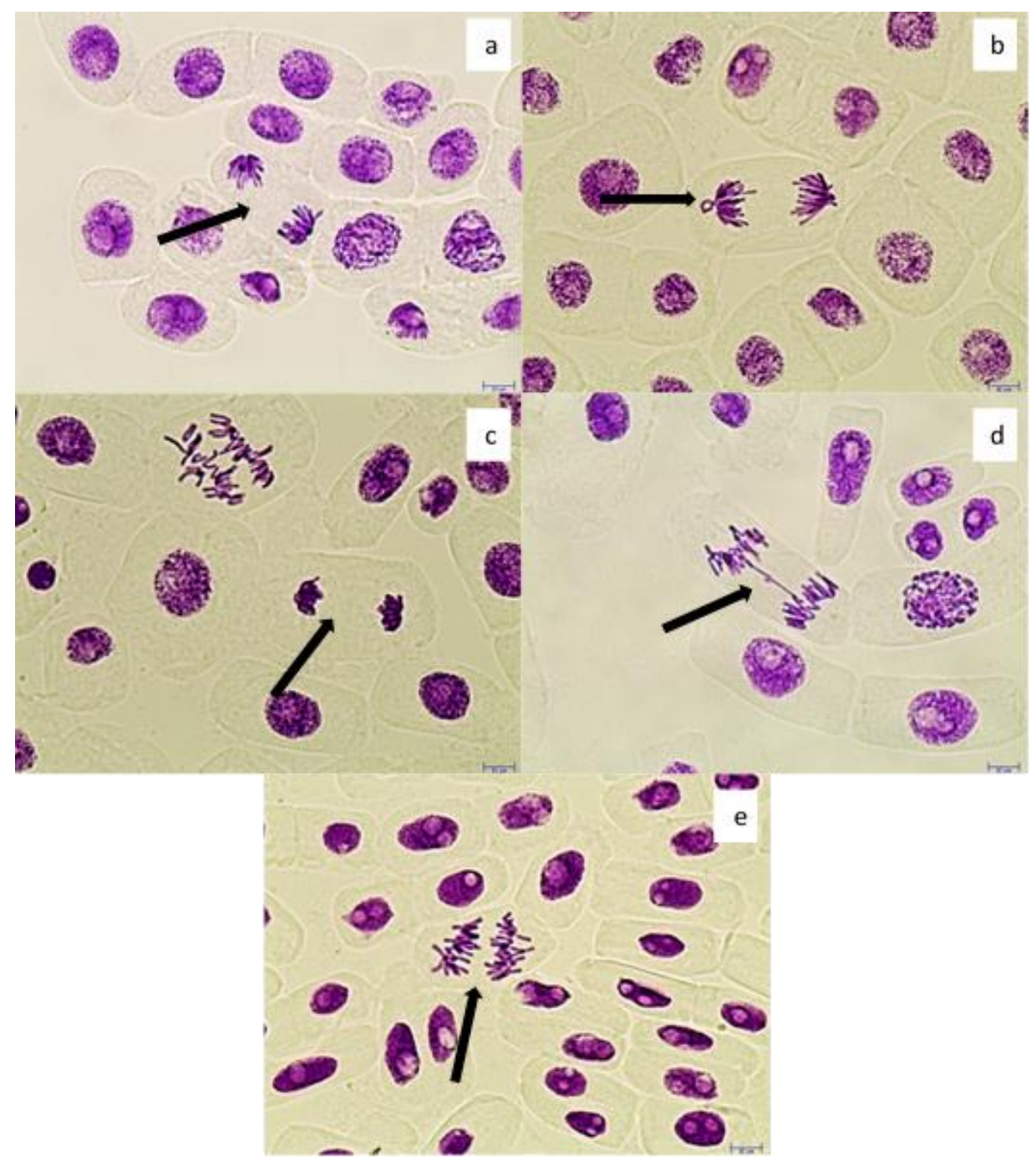

Şekil 2. PiP’e maruz bırakılmış A. cepa kök hücrelerinde görülen anafaz-telofaz anormallikleri a: Bozulmuş ana-telofaz, b: Kalgın kromozom, c: Yapışkanlık, d: Anafaz köprüsü, e-Poliploidi

Çizelge 4. PiP'in A. cepa kök hücre meristemlerinde Komet testi ile DNA hasarının tespiti

\begin{tabular}{ccllll}
\hline \multirow{2}{*}{ Uygulama } & $\begin{array}{c}\text { Konsantrasyon } \\
\text { (ppm) }\end{array}$ & \multicolumn{5}{c}{$\begin{array}{c}\text { DNA Hasarı (Arbitrary Unit) } \\
\text { Ortalama } \pm \text { Standart sapma }\end{array}$} \\
\cline { 3 - 6 } & $\mathbf{2 4}$ saat & $\mathbf{4 8}$ saat & $\mathbf{7 2 ~ s a a t}$ & $\mathbf{9 6}$ saat \\
\hline Kontrol & - & $2,33 \pm 0,58 \mathrm{a}$ & $4,33 \pm 0,58 \mathrm{a}$ & $6,33 \pm 0,58 \mathrm{a}$ & $6 \pm 1 \mathrm{a}$ \\
MMS & 10 & $132,33 \pm 4,51 \mathrm{~b}$ & $143,67 \pm 1,53 \mathrm{~b}$ & $146,67 \pm 2,89 \mathrm{~b}$ & $158,33 \pm 3,51 \mathrm{~b}$ \\
\hline \multirow{2}{*}{ Pip } & 50 & $43 \pm 2 \mathrm{c}$ & $52,67 \pm 0,58 \mathrm{c}$ & $63,33 \pm 3,06 \mathrm{c}$ & $73,33 \pm 3,51 \mathrm{c}$ \\
& 100 & $65,33 \pm 1,53 \mathrm{~d}$ & $70,67 \pm 2,52 \mathrm{~d}$ & $75 \pm 2 \mathrm{~d}$ & $86 \pm 3 \mathrm{~d}$ \\
& 200 & $101 \pm 2,65 \mathrm{e}$ & $106,67 \pm 2,08 \mathrm{e}$ & $110,33 \pm 2,08 \mathrm{e}$ & $121 \pm 4 \mathrm{e}$ \\
\hline
\end{tabular}

* Sütunlardaki farklı harfler $p<0,05$ düzeyinde önemli Duncan çoklu dağılım testi)

\section{Tartışma ve Sonuç}

Bu çalışma ile PiP'in $A$. cepa kök ucu meristem hücrelerinde oluşturduğu sito-genotoksik etkileri Allium ana-telofaz testi ile belirlenmiştir. Büyüme engelleme testi kullanılarak PiP'in $\mathrm{EC}_{50}$ değeri 100 ppm $(\% 50,29)$ olarak bulunmuştur. PiP'in kullanılan bütün dozları ortalama kök uzunluğunu istatistiksel olarak azaltmıştır. Kök büyümesinin engellemesi apikal meristematik aktivite (Webster and MacLeod
1996), farklılaşma sırasındaki hücre uzaması (Fusconi et al. 2006) ya da farklılaşma sırasında hücre duvarının kaybolmasını ve uzamasını uyaran enzim aktivitesi ile alakalı olabilir (Silveira et al. 2017). Neoseiulus womersleyi ve Phytoseiulus persimilis için $\mathrm{LC}_{50}$ değerleri sırasıyla 178.7 ve 98.1 $\mathrm{mg} / \mathrm{kg}$ (Park et al. 2011), Tetranychus urticae için 20446.5 ppm (Kim et al. 2006), Eisenia fetida için ise $0.55 \mu \mathrm{g} / \mathrm{cm}^{2}$ (Wang et al. 2012) bulunmuştur. LD $\mathrm{L}_{50}$ değeri Rana nigromaculata için 2716.1 \pm 437.8 
$\mathrm{mg} / \mathrm{kg}$, Bufo bufo için ise $4074.7 \pm 614.8 \mathrm{mg} / \mathrm{kg}$ bulunmuştur (Sicai and Hongbin 1995). IC $\mathrm{C}_{50}$ değeri HepG2 hücre hatlarında $1000 \mu \mathrm{M}^{\prime}$ dan daha fazladır (Ma et al. 2016).

PiP'in uygulanan tüm konsantrasyonları uygulama sürelerince Mi'yi istatistiksel olarak azaltmıştır. Mi'nin azalması PiP'in $A$. cepa kök hücrelerine sitotoksik etki gösterdiğinin göstergesidir. Kontrol grubu ile karşılaştırıldığında profaz indeksi azalmışken telofaz indeksi istatistiksel olarak artmıştır. Mi'deki anlamlı azalma $\mathrm{G}_{1}$ fazınının bloke edilmesi, $\mathrm{S}$ fazında DNA sentezinin baskılanması ya da inhibisyonu (Sudhakar et al. 2001; Gupta et al. 2018) veya $G$ fazının bloke edilmesi (El-Ghamery et al. 2000) gibi hücre siklusunun bozulmasından ya da mitotik faz süre değişikliklerinden (Saxena et al.) kaynaklanabilir. Ayrıca hücre siklusunda görev alan spesifik proteinlerin inhibisyonu (Hidalgo et al. 1989) ve ROS oluşumu da (Livanos et al. 2017) benzer etki yapmaktadır. Çalışmamızdan farklı olarak pyridaben insan lenfositlerinde istatistikse I olarak Mi'yi değiştirmemiştir (Dönbak 2017).

PiP ana-telofazdaki toplam KA'ları (bozulmuş anatelofaz, kalgın kromozom, yapışkanlık, anafaz köprüsü ve poliploidi) hem doza hem de zamana bağlı olarak arttırmış ve bu artışlar istatistiksel açıdan anlamlı bulunmuştur. PiP toplam KA'ları artırarak $A$. серa kök hücrelerine genotoksik etki göstermiştir. Bozulmuş ana-telofaz (Şekil 2a) ve kalgın kromozom (Şekil2b), kromozomların kutuplara tam olarak hareket edememesi, iğ yapısının deformasyonundan ya da bozulmuş mikrotübüllerden kaynaklanabilir (Evseeva et al. 2005, Kumari et al. 2009, Singh and Roy 2017). Genellikle kromozomlar üzerinde geri dönüşümsüz etkiye sebep olan yapışkanlık (Şekil 2c); DNA-DNA veya DNA-protein çapraz bağlanmalarına neden olur. Artan kromozom kısalması ve yoğunlaşması, muhtemelen DNA'nın depolimerizasyonu ve nükleoproteinlerin kısmi çözünmesinden veya kromatin liflerinin ekstra kromozomal ile iç içe geçmesinden kaynaklanabilir (Fiskesjö and Levan 1993, Türkoğlu 2015, El-Ghamery and Mousa 2017). Kullanılan kimyasal maddelerin klastojenik etkisi sonucu kromozomların kırılması ya da füzyonu, eşit olmayan kromatid değişimi, disentrik kromozomdan dolayı, replikasyon enzimlerinin aktivasyonunun değiştirilmesinden veya yapışkanlıktan dolayı oluşabilen (El-Ghamery et al. 2000, Luo et al. 2004) anafaz köprüsüne (Şekil 2 d) en çok 72 saatlik uygulama süresinin 100 ppm'lik konsantrasyonunda (\%2.8) tespit edilmiştir. Poliploidi (Şekil 2e) sitokinezin normal işleyişinin bozulması sonucu fragmoplast oluşumunda zorluklara yol açabilir (Fernandes et al. 2007). Pyridabenin 5, 10, 20 ve 40 $\mu \mathrm{g} / \mathrm{mL}$ konsantrasyonları insan periferal lenfositlerinde KA'yı, kardeş kromatid değişimini ve mikronükleus oluşumunu uyararak genotoksik etki göstermiştir (Dönbak 2017). Pyridaben ST486 ve EW36 hücre hatlarında apoptozisi indüklemiştir (Bloom et al. 2005). EFSA'ya (2010) göre pyridaben genotoksik, karsinojenik, nörotoksik ya da üreme toksisitisitesi göstermemektedir. Igarashi ve Sakamoto (1994) ticari şirketlerin verilerine dayanarak pyridabenin bakteriyel ve memeli test sistemlerinde nokta mutasyonlarını, in vitro KA'ları, in vivo mikronükleus oluşumunu ve bakteriyel test sistemlerinde DNA hasarını uyarmadıklarını belirtmişlerdir.

PIP DNA hasarını kontrol grubuna göre istatistiksel olarak arttırmış fakat bu artışlar MMS'den düşük bulunmuştur. Pyridaben Balb/C farelerinde DNA hasarını ve kromatin anormalliklerini (Manas et al. 2013a), ROS ve NOS seviyelerini (Manas et al. 2013b, 2014) istatistiksel olarak artırmıştır. Aynı zamanda N27 hücrelerinde 60 ve 180 dakikalık $3 \mu \mathrm{M}$ pyridaben uygulanması ROS oluşumu indüklenmiştir (Charli et al. 2016). S-K-N-MC neuroblastoma hücrelerinde $10 \mathrm{nmol} / \mathrm{L}$ pyridaben aynı miktardaki rotenona göre oksidatif hasarı daha fazla oranda arttırmıştır (Sherer et al. 2007). Pyridabenin oluşturduğu DNA hasarı mitokondriyel elektron taşıma sistemindeki Kompleks I'in inhibe edilerek ROS miktarının artmasından kaynaklanabilir (STPierre et al. 2002, Chen et al. 2003).

Sonuç olarak PIP, A. cepa kök meristematik hücrelerinde sitototoksik etki göstererek kök büyümesini ve Mi'yi azaltmakla beraber genotoksik etki göstererek KA'ları ve DNA hasarını artırmıştır. PiP kullanımına dikkat edilmeli ve sito-genotoksik etkileri diğer test sistemleri ile de araştırılmalıdır. 


\section{Kaynaklar}

Bloom, S.E., Lemley, A.T. and Muscarella, D.E., 2005. Potentiation of apoptosis by heat stress plus pesticide exposure in stress resistant human Blymphoma cells and its attenuation through interaction with follicular dendritic cells: role for cJun N-terminal kinase signaling. Toxicological Sciences, 89, 214-223.

Bose, A. and Beal, M.F., 2016. Mitochondrial dysfunction in Parkinson's disease. Journal of Neurochemistry. 139, 216-231.

Caritá, R. and Marin-Morales, M.A., 2008. Induction of chromosome aberrations in the Allium cepa test system caused by the exposure of seeds to industrial effluents contaminated with azo dyes Chemospher, . 72, 722-725.

Chaparro, T.R., Botta C.M. and Pires, E.C., 2010. Biodegradability and toxicity assessment of bleach plant effluents treated anaerobically. Water Science and Technology, 62, 1312-1319.

Charli, A., Jin, H., Anantharam, V., Kanthasamy, A. and Kanthasamy, A.G., 2016. Alterations in mitochondrial dynamics induced by tebufenpyrad and pyridaben in a dopaminergic neuronal cell culture model. Neurotoxicology, 53, 302-313.

Chen, Q., Vazques, E.J., Moghaddas, S., Hoppel, C.L. and Lesnefsky, E.J., 2003. Production of reactive oxygen species by mitochondria: Central role of complex III. Journal of Biological Chemistry, 278, 3602736031.

Dhawan, A., and Anderson, D., 2016. The comet assay in toxicology (Vol. 30). Second Edition. Royal Society of Chemistry. 3-64.

Dönbak, D.B., 2017. İnsan periferal lenfositlerinde pyridaben insektisitinin $\mathrm{ka}$, kkd ve $\mathrm{mn}$ testleri ile genotoksisitesinin değerlendirilmesi, Yüksek Lisans Tezi, Kahramanmaraş Sütçü İmam Üniversitesi, Fen Bilimleri Enstitüsü. Kahramanmaraş. 88.

El-Ghamery, A.A. and Mousa, M.A., 2017. Investigation on the effect of benzyladenine on the germination, radicle growth and meristematic cells of Nigella sativa L. and Allium cepa L. Annals of Agricultural Sciences, 62, 11-21.

El-Ghamery, A.A., El-Nahas, A.I. and Mansour, M.M., 2000. The action of atrazine herbicide as an indicator of cell division on chromosomes and nucleic acid content in root meristems of Allium cepaand Vicia faba. Cytologia, 65, 277-287.

European Food Safety Authority (EFSA)., 2010. Conclusion on the peer review of the pesticide risk assessment of the active substance pyridaben. EFSA Journal, 8, 1632.
Evseeva, T.I. Geras'kin, S.A., Shuktomova, I.I. and Taskaev, A.I., 2005. Genotoxicity and cytotoxicity assay of water sampled from the underground nuclear explosion site in the north of the Perm region (Russia), Journal of Environmental Radioactivity, 80, 59-74.

Fernandes, T.C.C., Mazzeo, D.E.C. and Marin-Morales, M.A., 2007. mechanism of micronuclei formation in polyploidizated cells of Allium cepa exposed to trifluralin herbicide. Pesticide Biochemistry and Physiology, 88, 252-259.

Fiskesjö, G. and Levan, A., 1993. Evaluation of the first ten MEIC chemicals in the Allium test. Alternatives to Laboratory Animals, 21, 139-149.

Fiskesjö, G., 1985. The Allium test as a standard in environmental monitoring. Hereditas, 102, 99-112.

Fusconi, A., Repetto, O., Bona, E., Massa, N., Gallo, C., Dumas-Gaudot, E. and Berta, G., 2006. Effect of cadmium on meristem activity and nucleus ploidy in roots of Pisum sativum L. cv. Frisson seedligs. Environmental and Experimental Botany, 58. 253260.

Gichner, T., Znidar, I., Wagner, E.D. and Plewa, M.J., 2009. The use of higher plants in the Comet assay, A.. Dhawan. D.. Anderson. the Comet Assay in Toxicology. Pesticide Biochemistry and Physiology. Ukrayna. (pp. 98-119).

Gomez, C., Bandez, M.J. and Navarro, A., 2007. Pesticides and impairment of mitochondrial function in relation with the parkinsonian syndrome. Frontiers in Bioscience, 12, 1079-1093.

Gupta, K., Mishra, K., Srivastava, S. and Kumar, A., 2018. Cytotoxic assessment of chromium and arsenic using chromosomal behavior of root reristem in Allium cepa L. Bulletin of Environmental Contamination and Toxicology, 100, 803-808.

Hidalgo, A., Gonzales-Reyes, J.A., Navas, P. and GarciaHerdugo, G., 1989. Abnormal mitosis and growth inhibition in Allium cepa roots induced by propham and chlorpropham. Cytobios, 57, 7-14.

Igarashi, H. and Sakamoto, S., 1994. Summary of toxicity studies with pyridaben, Journal of Pesticide Science, 29, 243-251.

Jana, A., Ghosh, M., Sinha, S., Jothiramajayam, M., Nag, A. and Mukherjee, A., 2017. Hazard identification of coal fly ash leachate using a battery of cytogenotoxic and biochemical tests in Allium cepa. Archives of Agronomy and Soil Science, 63, 14431453.

Kaya, N., Çakmak, I., Akarsu, E. and Kaya, B., 2015. DNA damage induced by silica nanopartıcle. Fresenius Environmental Bulletin, 24, 4478-4484. 
Kaygisiz, Ş.Y. and Ciğerci, i..H., 2017. Genotoxic evaluation of different sizes of iron oxide nanoparticles and ionic form by SMART, Allium and comet assay. Toxicology and Industrial Health, 33, 802-809.

Kim, M., Sim, C., Shin, D., Suh, E. and Cho, K., 2006. Residual and sublethal effects of fenpyroximate and pyridaben on the instantaneous rate of increase of Tetranychus urticae. Crop Protection, 25, 542-548.

Kocyigit, A., Keles, H., Selek, S., Guzel, S., Celik. H. and Erel, O., 2005. Increased DNA damage and oxidative stress in patients with cutaneous leishmaniasis. Mutation Research/Genetic Toxicology and Environmental Mutagenesis, 585, 71-78.

Kumari, M., Mukherjee, A. and Chandrasekaran, N., 2009. Genotoxicity of silver nanoparticles in Allium cepa. Science of The Total Environment, 407, 5243-5246.

Küçük, D. and Liman, R., 2018. Cytogenetic and genotoxic effects of 2-chlorophenol on Allium cepa L. root meristem cells. Environmental Science and Pollution Research, 25, 6117-36123.

Liman, R., 2013. Genotoxic effects of Bismuth (III) oxide nanoparticles by Allium and Comet assay. Chemosphere, 93, 269-273.

Liman, R., Ciğerci, i.H. and Öztürk, N.S., 2015. Determination of genotoxic effects of imazethapyr herbicide in Allium cepa root cells by mitotic activity, chromosome aberration and comet assay. Pesticide Biochemistry and Physiology, 118, 38-42.

Liman, R., Acikbas, Y. and Ciğerci, I..H., 2019. Cytotoxicity and genotoxicity of cerium oxide micro and nanoparticles by allium and comet tests. Ecotoxicology and Environmental Safety, 168, 408414.

Livanos, P., Galatis, B., Quader, H. and Apostolakos, P., 2017. ROS homeostasis as a prerequisite for the accomplishment of plant cytokinesis. Protoplasma, 254, 569-586.

Luo, L.Z., Werner, K.M., Gollin, S.M. and Saunders, W.S., 2004. Cigarette smoke induces anaphase bridges and genomic imbalances in normal cells. Mutation Research/Fundamental and Molecular Mechanisms of Mutagenesis, 554, 375-385.

Ma, M., Chen, C., Yang, G., Li, Y., Chen, Z. and Qian, Y., 2016. Combined cytotoxic effects of pesticide mixtures present in the Chinese diet on human hepatocarcinoma cell line. Chemosphere, 159, 256266.

Manas, G.E., Parivar, K., Hasanzadeh, S., Yaghmayi, P. and Najafi, G., 2014. The effects of pyridaben pesticide on gonadotropic, gonadal hormonal alternations, oxidative and nitrosative stresses in Balb/C mice strain. Comparative Clinical Pathology, 23, 297303.

Manas, G.E., Hasanzadeh, S., Najafi, G., Parivar, K. and Yaghmaei, P., 2013a. The effects of pyridaben pesticide on the DNA integrity of sperms and early in vitro embryonic development in mice. Iranian Journal of Reproductive Medicine, 11, 605-610.

Manas, G.E., Hasanzadeh, S. and Parivar, K., 2013b. The effects of pyridaben pesticide on the histomorphometric, hormonal alternations and reproductive functions of $\mathrm{BALB} / \mathrm{C}$ mice. Iranian journal of Basic Medical Sciences, 16, 1055-1064.

Mauro, M.O., Pesarini, J.R., Marin-Morales, M.A., Monreal, M.T.F.D., Monreal, A.C.D., Mantovani, M.S. and Oliveira, R.J., 2014. Evaluation of the antimutagenic activity and mode of action of the fructooligosaccharide inulin in the meristematic cells of Allium cepa culture. Genetics and Molecular Research. 13, 4808-4819.

Palmieri, M.J., Andrade-Vieira, L.F., Trento, M.V.C., de Faria Eleutério, M.W., Luber, J., Davide, L.C. and Marcussi, S., 2016. Cytogenotoxic effects of spent pot liner (SPL) and its main components on human leukocytes and meristematic cells of Allium cepa. Water, Air, \& Soil Pollution, 227, 156-166.

Park, J.J., Kim, M., Lee, J.H., Shin, K.I., Lee, S.E., Kim, J.G. and Cho, K., 2011. Sublethal effects of fenpyroximate and pyridaben on two predatory mite species, Neoseiulus womersleyi and Phytoseiulus persimilis (Acari, Phytoseiidae). Experimental and Applied Acarology, 54, 243-259.

Rahman, M.M., Rahman, M.F. and Nasirujjaman, K., 2017. A study on genotoxicity of textile dyeing industry effluents from Rajshahi, Bangladesh, by the Allium cepa test. Chemistry and Ecology, 33, 434-446.

Rand, G.M. and Clark. J.R., 2000. Hazard/risk assessment of pyridaben: I. Aquatic toxicity and environmental chemistry. Ecotoxicology, 9, 157-168.

Santos, C.L., Pourrut, B. and Oliveira, J.M.P., 2015. The use of comet assay in plant toxicology: recent advances. Frontiers in Genetics, 6. 216.

Saxena, P.N., Chauhan, L.K.S. and Gupta, S.K., 2005. Cytogenetic effects of commercial formulation of cypermethrin in root meristem cells of Allium sativum: spectroscopic basis of chromosome damage. Toxicology, 216, 244-252.

Sherer, T.B., Richardson, J.R., Testa, C.M., Seo, B.B., Panov, A.V., Yagi, T. and Greenamyre, J.T., 2007. Mechanism of toxicity of pesticides acting at complex I:relevance to environmental etiologies of 
Parkinson's disease. Journal of Neurochemistry, 100, 1469-1479.

Sicai, H. and Hongbin, T., 1995. Study on the acute toxicity of three acaricides to frog and toad. Pesticides, 6, 14-22.

Silveira, G.L., Lima, M.G.F., dos Reis, G.B., Palmieri, M.J. and Andrade-Vieria, L.F., 2017. Toxic effects of environmental pollutants: Comparative investigation using Allium cepa L. and Lactuca sativa L. Chemosphere, 178, 359-367.

Singh, D. and Roy, B.K., 2017, Evaluation of malathioninduced cytogenetical effects and oxidative stress in plants using Allium test. Acta Physiologiae Plantarum, 39, 92-102.

ST-Pierre, J., Buckingham, J.A., Roebuck, S.J. and Brand, M.D., 2002. Topology of superoxide production from different sites in the mitochondrial electron transport chain. Journal of Biological Chemistry, 277, 44784-44790.

Sudhakar, R., Ninge Gowda, K.N. and Venu, G., 2001. Mitotic abnormalities induced by silk dyeing industry effluents in the cells of Allium cepa. Cytologia, 66, 235-239.

Tice, R.R., Agurell, E., Anderson, D., Burlinson, B., Hartmann, A., Kobayashi, H. and Sasaki, Y.F., 2000. Single cell gel/comet assay: guidelines for in vitro and in vivo genetic toxicology testing. Environmental and Molecular Mutagenesis, 35, 206-221.

Türkoğlu, Ş., 2015. Evaluation of genotoxic effects of five flavour enhanc.ers (glutamates) on the root meristem cells of Allium cepa. Toxicology and industrial Health, 31, 792-801.

Wang, Y., Wu, S., Chen, L., Wu, C., Yu, R., Wang, Q. and Zhao, X., 2012. Toxicity assessment of 45 pesticides to the epigeic earthworm Eisenia fetida. Chemosphere. 88, 484-491.

Webster, P.L. and Macleod, R.D., 1996. The root apical meristem and its magrin. In: Waishel. Y.. Eshel. A.. Kafkafi. U.. Plant roots. The hidden half (Second Ed.), Marcel Dekker, New York. 51, 76-79.

$\mathrm{Yu}$, S.J., 2008. The toxicology and biochemistry of insecticides. CRC Press, Taylor and Francis group, New York. ISBN. 25-85.

\section{internet kaynakları}

1-http://www.safatarim.com/PDF/Documents/138primite-20-wp-primite-20-wp---brosur.pdf

(18.12.2018) 